\title{
ERP implementation at SMEs: analysis of five Canadian cases $^{1,2}$
}

\author{
Brent Snider ${ }^{3}$, Giovani J.C. da Silveira and Jaydeep Balakrishnan \\ Haskayne School of Business, University of Calgary \\ 2500 University Drive NW, Calgary, Alberta, Canada T2N $1 N 4$
}

Published in the International Journal of Operations and Production Management,

29, 1, 2009, pp 4-29.

\footnotetext{
${ }^{1}$ A previous and shorter version of this paper appeared in the proceedings from the 35th Annual Meeting of the Western Decision Sciences Institute, Waikoloa, Hawaii, April 2006. Professor da Silveira's research is supported by the Natural Sciences and Engineering Research Council of Canada, Discovery Grant \# 283134-04.

${ }^{2}$ We sincerely thank the reviewers for suggestions that helped us to significantly improve the paper.

${ }^{3}$ Corresponding author. Phone 403-220-7164. Email brent.snider@ haskayne.ucalgary.ca.
} 


\section{ERP implementation at SMEs: analysis of five Canadian cases}

\section{Abstract}

Purpose - This paper explores the Critical Success Factors (CSFs) of Enterprise Resource Planning (ERP) system implementation at Small and Medium sized Enterprises (SMEs).

Design/methodology/approach - Five case studies of Canadian SMEs were conducted. They included interviewing individuals from five roles at each organization and gathering project documents. Following an evaluation of each project's success (within-case analysis), cross-case analysis was conducted to elicit influential and distinctive factors.

Findings - We identified factors that appeared to explain variation between successful and unsuccessful implementations at SMEs, besides factors that appeared to be innovative or counterintuitive in light of the established literature.

Research limitations/implications - The study reinforces the need for more research that is focused on SMEs. All cases were of Canadian SMEs with either a manufacturing or distribution focus, potentially limiting the generalizability of findings to other industries or countries.

Practical implications - By identifying relevant CSFs for SMEs, managers can better prioritize implementation efforts and resources to maximize success of ERP implementations.

Originality/value - This appears to be one of the first studies to focus on the CSFs of ERP implementation at SMEs.

Keywords - Implementation, Enterprise Resource Planning, multiple case studies, triangulation.

Paper type - Research paper 


\section{Introduction}

Small and Medium sized Enterprises (SMEs) are of critical importance to many economies. Firms with less than 500 employees provided $51 \%$ of all employment in the United States as of March, 2004 (US Census Bureau, 2004) and 64\% of all Canadian private sector employment in 2005 (Industry Canada, 2006). In the European Union, firms with 250 employees or less provided 67\% of employment outside the financial industry in 2003 (Eurostat, 2007). While SMEs are integral part of these economies, they also face numerous challenges in implementing technologies such as Enterprise Resource Planning (ERP) systems, including a lack of human and financial resources to support such initiatives (McAdam, 2002; Achanga et al., 2006).

Like many other technological advances, ERP systems were initially implemented mostly at large organizations. Their relative absence from SMEs has probably been the main reason for the research focus on large companies (e.g. Somers and Nelson, 2001; Mabert et al., 2003b; Mandal and Gunasekaran, 2003; Umble et al., 2003; Nah and Delgado, 2006). More recently, however, vendors began to provide SME-specific ERPs (Bingi et al., 1999; Bell and Orzen, 2007; Deep et al., 2008). ERP adoption at SMEs has been catching up with large companies (Van Everdingen et al., 2000; Mabert et al., 2003a).

Given that SMEs are significantly different from large organizations (Lee and Oakes, 1995; Ghobadian and Gallear, 1996), and that more and more SMEs are implementing ERPs, the relevant question would be, "what factors may influence ERP implementation success in SMEs, and why?" This study aims to answer that question by studying ERP implementations at SMEs. To the best of our knowledge, only Muscatello et al. (2003) and Loh and Koh (2004) have specifically tackled this challenge, even though the former focused on subsidiaries of larger firms, and while the latter used interviews as support for findings, the listed CFSs appeared to be 
mainly based on their literature review. Finally, Adam and O’Doherty (2000) studied Irish organizations including SMEs; however, their focus was on implementation partnership and duration. Thus, it appears there is a need and opportunity for new studies focused on the success factors of ERP implementation at SMEs.

This paper is structured as follows. First, we review the literature mainly to identify ERP Critical Success Factors (CSFs) in general organizations. Next, we describe the data collection and within-case analysis in this multiple case research. We then present and discuss the factors that emerged from the cross-case analysis. Finally, we present the study contributions, limitations, and conclusions highlighting implications for research and practice.

This paper contributes to research on ERPs in three main ways. First, it identifies factors that may distinguish upon successful and unsuccessful ERP implementations in SMEs. Second, it explains how and why specific factors may apply in particular to SMEs. Third, it reinforces the need for more research that is focused on information technology (IT) in SMEs.

\section{Background}

ERP

ERPs emerged by the early 1990s by integrating programs that in previous decades existed separately across functional areas (Jacobs and Weston Jr., 2007). According to Markus et al. (2000b), ERPs emerged from the attempt to expand traditional MRP II systems to incorporate activities outside the production scope. Mabert et al. (2003b) defined ERPs as “... enterprisewide on-line interactive systems that support cross-functional processes using a common database" (p. 302). Al-Mashari et al. (2003) suggested that a basic ERP consisted of a database, an application, and an integrated interface. Jacobs and Bendoly (2003) described ERPs as 
corresponding to "... corporate infrastructures, much in the same way that physical highway systems do" (p. 234). Davenport (1998) defined ERPs as "complex pieces of software" (p. 122) whose implementation demanded great resources; they might deliver benefits, but as Bingi et al. (1999) also suggested, implementation failure might have fatal consequences.

Various authors developed lists of ERP CSFs that were primarily based on studies at large organizations. Loh and Koh (2004: 3440) classified CSFs from studies published between 1988 and 2000 into the three stages of "preparation, analysis \& design", "implementation", and “maintenance". Our review (in Table I), similar to Loh and Koh's (2004) review, updates and complements the summary by summarizing the CSFs from studies published after the year 2000 (besides Esteves-Souza and Pastor-Collado's [2000] study, that was not in their matrix). Our update excludes some additional recent studies that have either focused on a few particular CSFs, e.g. Robey et al. (2002), or developed theoretical frameworks based on a more limited number of sources, e.g. Akkermans and van Helden (2002). As in Loh and Koh (2004), we divided CSFs into three stages. Pre-implementation factors include variables of strategy and structure. Implementation factors typically occur between software selection and going live. Postimplementation relates to follow-up after going live.

\section{Take in Table I}

\section{SMEs}

The literature points out significant differences between SMEs and large organizations. SME top management is usually involved in day-to-day activities (McCartan-Quinn and Carson, 2003). However, managers may have limited formal training (Lee and Oakes, 1995). Absence of longterm planning is another dominant factor (Gunasekaran et al., 1996). On the other hand, SMEs 
have relatively informal structures and culture (Mintzberg et al., 2003, p. 217), which increase cross-functional exchanges, and small management teams, which results in efficient decisionmaking (Ghobadian and Gallear, 1996; McAdam, 2000). These later issues have been considered particularly advantageous for major projects (Lee and Oakes, 1995).

One major disadvantage of SMEs is lack of human and financial resources (Ghobadian and Gallear, 1996; Gunasekaran et al., 1996; McAdam, 2002; Achanga et al., 2006). Achanga et al. (2006) stressed that staff shortages at SMEs might even require production to halt during training. Skills upgrading may be needed, however SMEs often cannot afford extensive training (Raymond et al., 1998). Furthermore, they may face challenges in paying for major consulting (Kinni, 1995). Sun et al. (2005) indicated that such resource shortages might hinder project success.

Regarding IT, SMEs seldom have dedicated IT staff, let alone a formal department (Adam and O’Doherty, 2000; Mabert et al., 2003a). Major projects face increased external and internal risks when compared to large organizations. Externally, SMEs are more fragile than large companies (Rao, 2000; Shin, 2006) and face greater difficulty in obtaining credit (Lu, 2006). Such external risks can lead to project delays or even abandonment (Serafeimidis and Smithson, 1999). Internally, SMEs may find it difficult to implement reengineering projects due to limited spare resources (Eshelman et al., 2001; McAdam, 2002). Overall, they may face greater challenges in adopting technology (Raymond et al., 1998; Shin, 2006). Finally, the cost of an ERP implementation may be proportionally higher for SMEs than for large organizations (Mabert et al., 2000), and SMEs may be more severely impacted by unsuccessful implementations (Muscatello et al., 2003). 


\section{ERP implementation at SMEs}

Various researchers have recommended research into the implementation and use of ERPs at SMEs (e.g. Bernroider and Koch, 2001; Huin et al., 2003; Jacobs and Bendoly, 2003; Mabert et al., 2003a; Muscatello et al., 2003; Sun et al., 2005). Huin (2004) argues that unless differences between small and large firms are understood, managing ERP projects in SMEs “... will continue to be slow, painful and at times even unfruitful” (p. 516).

However, not many studies appear to have tackled this challenge yet. Loh and Koh's (2004) review of the literature identified $10 \mathrm{CSFs}$, which were then confirmed by interviews across eight SMEs from the UK. Soja's (2006) ERP survey in Poland identified 16 factors at large organizations but only two (out of 26) at firms with less than 300 employees. Muscatello et al. (2003) studied four US manufacturing SMEs, however they were all subsidiaries of large firms and they all had annual revenues greater than US\$ 50 million. Buonanno et al. (2005) explored the antecedents of ERP adoption in Italian large firms and SMEs. These and a few other studies, e.g. Adam and O'Doherty (2000) and Shin (2006) provided valuable insights into the dynamics of ERP implementation at SMEs.

Thus, it appears from previous studies that organizational conditions at SMEs differ from that of large organizations. This suggests that the relative importance of CSFs in ERP implementation may also differ. Since literature on ERP implementation at SMEs is relatively sparse, our paper helps to narrow this knowledge gap by investigating ERP implementation at SMEs. 


\section{Methodology}

\section{Research approach}

Research on ERPs has followed a progression that may be typical for new technologies (Jacobs and Bendoly, 2003). Survey studies identified ERP success factors, e.g. Hong and Kim (2002), and provided statistics on ERP adoption and benefits, e.g. Jones and Young (2006). Case study research (Gattiker, 2002; Ash and Burn, 2003; Mandal and Gunasekaran, 2003; Muscatello et al., 2003; Umble et al, 2003; Nah and Delgado, 2006) explored the nature and role of ERP success factors. However, since they mostly focus on large companies, and SME characteristics differ from large organizations, these studies may not explain ERP success in SMEs. For that reason, we chose to carry out in-depth and multiple case study research to provide insight into what explains ERP success at SMEs, which might not be possible with other methods. In particular, we aimed to investigate how and why CSFs that were previously identified in the literature might or might not explain ERP success in the SME context. Our use of the case study method we believe sheds additional insight on the factors that affect ERP implementation in SMEs.

As a consequence of the in depth nature of the investigation, case studies are inherently very time consuming. Thus sample sizes were limited; in our case it consisted of one pilot and five actual studies. The effect of small sample size was mitigated by carefully selecting the participating companies and by following Pettigrew's (1990) protocol as explained in the following paragraphs.

Meredith (1998), Eisenhardt (1989) and Stuart et al. (2002) suggested that using case studies is best when existing perspectives seem not fit to new contexts. According to Morris et al. (1999), 
ethnographic research based on interviews and analysis of content is useful to explore phenomena from inside out, “... to describe a particular culture in its own terms" (p. 781).

Miles and Huberman (1994: 26) argued that multiple cases provide “... an even deeper understanding of processes and outcomes of cases, the chance to test (not just develop) hypotheses, and a good picture of locally grounded causality". In accordance with the norm for building theory from case studies, this research is based on "theoretical sampling" (Eisenhardt, 1989) to provide literal and theoretical replication (Yin, 1994).

Following this guidance, multiple Value Added Resellers (independent businesses that resell software and provide implementation related consulting services) were requested to identify organizations that had "successful" or "unsuccessful" implementations. Situations of "successful" or "unsuccessful" ERP system implementations were selected following Pettigrew's (1990) recommendations for the choice of research settings: (i) the phenomenon must be "transparently observable" (p. 275); (ii) cases must represent “... polar types.... which illustrate high and low performance" (p. 275); and (iii) cases must be clearly familiar with the research phenomenon. These three criteria guided both the choice (invitation) and confirmation (after acceptance by each company) of organizations to be used as case studies. Hence, each participating company was required to:

- Be a small (i.e. with less than 49 employees) or medium (i.e. between 50 and 499 employees) sized business (the focus of the study);

- Have implemented ERP within the previous 36 months, and used it for six months or more. This was so that the organization had some reasonable time to assess the impact of 
the new system, while also ensuring that the implementation was reasonably recent to facilitate interviews and document retrieval (following recommendations i and iii);

- Be in the manufacturing or distribution business. These organizations typically use more ERP modules than service organizations, which increases the complexity of the project and in turn provides richer research data (following recommendations i and iii);

- The final choice of companies had to provide a balanced number of 'successful' and 'unsuccessful' cases to be used in the analysis (following recommendation ii).

Eleven companies were contacted with a recruitment letter. Six companies declined due to insufficient time or the departure of employees who played a major role in their ERP projects. Five companies agreed to participate in the study. The five cases exceeded the minimum number of four required for multi-case research (Eisenhardt, 1989), and conformed to the choice criteria discussed above. Thirty-four separate interviews were conducted with 20 individuals at those five companies. All companies were located in Canada.

At least two other studies focused on ERP implementations in Canadian companies. Kumar et al. (2002) emphasized ERP adoption processes; they called for further studies focused on the analysis and impact of ERPs in business organizations. More recently, Raymond and Uwizeyemungu (2007) investigated the contextual variables that might serve as antecedents to ERP implementation by Canadian SMEs.

\section{Data collection}

Different tactics were employed to improve construct validity. Primarily they included a pilot case (Yin, 1994; Herzog, 1996; Sapsford and Jupp, 1996), and triangulation (Eisenhardt, 1989; Yin, 1994). 
The pilot study case was representative of the intended case companies, as it met all of the criteria to participate in the study (Sapsford and Jupp, 1996). Further criteria for selecting the pilot case were accessibility and data availability (Yin, 1994). Access to the pilot company was facilitated by personal contacts of one of the researchers. Furthermore, the pilot company retained extensive documentation from their implementation, including detailed project meeting minutes and budgets. Seven interviews with four individuals were conducted over two months. The pilot study provided insight into scheduling interviews with multiple individuals, interviewing times (about 30 to 45 minutes each), and analyzing a large volume of data from interview transcripts and documents. Furthermore, minor revisions were made to question wording to improve clarity and flow of interviews.

Two of Patton's (1987) four triangulation approaches were employed in this study: (i) project documents supplied methodological triangulation and (ii) priority questions were asked to multiple interviewees to supply data triangulation. Each case involved seven separate interviews of people in five organizational roles: one interview each with the Chief Executive Officer (CEO) (except for Company 1, whose CEO was unavailable), the accounting manager, the operations manager, and one internal project team member, and three interviews with the internal project leader (at four companies, the internal project leader was also either the operations manager or the accounting manager, so each of them provided four interviews in total). In summary, four people gave four interviews each, one person gave three interviews, and the remaining fifteen gave one interview each. All interviews were transcribed. All of the 20 individual participants had the opportunity to edit the transcript (minor edits occurred in 11 of 34 transcripts); all interviewees provided written confirmation that the transcript accurately reflected their responses. 
While quantitative research uses statistical analysis for generalization to populations, qualitative research is focused on analytical generalization in the form of propositions (Yin, 1994). Besides providing the analyst with a more thorough understanding, multiple case studies help to increase generalizability well beyond drawing conclusions from a single case (Hillebrand et al., 2001).

Various tactics were employed to establish reliability of the study, as recommended by Yin (1994) and Herzog (1996). First, as many steps of the research as possible were documented. Second, a formal and presentable database of interviews and documents was prepared. Third, one of the researchers was the only interviewer, enabling this activity to be consistently performed across cases. Fourth, this research adhered to the four aspects that Yin (1994) described in how to establish a chain of evidence, further increasing the reliability of the study.

\section{Data analysis}

Content analysis uses a set of procedures to make analytical inferences from qualitative data (Weber, 1990). It is based on developing and applying a coding scheme to data. Weber's (1990) steps for creating a coding scheme were employed and, as Herzog (1996) recommended, rules were developed for each code to improve reliability and accuracy of the analysis. Codes were not developed until after all data was collected to make the analysis more context-sensitive compared to using a prefabricated coding list (Miles and Huberman, 1994). Furthermore, the coding scheme was revised based on an iterative process of testing on sample qualitative data until it was considered highly reliable. Approximately 150 single-spaced pages of interview transcripts were categorized into 1135 separate units of text. Following the rationale in Eisenhardt (1989) and 
Miles and Huberman (1994), each case was individually examined prior to the cross-case analysis.

Since the level of implementation success was the starting point for the cross-case analysis, clear success criteria were required. Our study defined success relating to the extent that potential benefits were achieved (Davenport, 1998), the costs associated with achieving those benefits, and the duration since going live (Markus et al., 2000a). Shang and Seddon's (2000) typology of benefits was used as a starting point and further detailed based on the literature including Mabert et al., (2000), Stefanou (2001), Jacobs and Bendoly, (2003), and Olhager and Selldin (2003). Cross-case analysis was carried out to improve understanding and explanation, and to increase generalizability of the findings (Miles and Huberman, 1994). The cross case analysis was conducted with clusters of successful and unsuccessful projects to identify patterns in findings (Stuart et al. 2002). The process used for classifying each case as successful or unsuccessful is described in the next section. This assessment helped the researchers to distinguish between influential and non-influential factors across the cases.

Overall, the analysis was heavily based on grounded theory as described in Strauss and Corbin (1990), including the content analysis and within-case analysis stages. However, Miles and Huberman's (1994) more structured approach was also employed to aid in the cross-case analysis, with tools such as meta-matrices being used.

\section{Case study companies}

All five companies reported common motivations for implementing a new ERP, namely solving legacy system issues (e.g. lack of integration, untrustworthy data, etc.) and having a scalable solution to handle business growth. At a minimum, all companies were utilizing the purchasing, 
sales, inventory, and accounting modules of their software packages. Table II provides demographic information for each case.

\section{Take in Table II}

\section{Variables}

Benefits. Multiple participants at each company were asked to rate the extent of cumulative benefits specifically attributable to the project. Seven-point Likert scales with endpoints -3 ("very negative") and +3 ("very positive") were applied to benefit categories previously developed from the literature (as discussed above), and used to prompt discussion of potential benefits. Cumulative results were adjusted for time since implementation (as explained below). Eight benefit categories were used to assess implementation success. Interview responses and project documents were used to substantiate scale values. Case 4 in particular revealed inconsistencies for some benefit categories. For example, an average rating of +1.7 was recorded for managerial benefits; however, CEO's comments such as "the visibility of key performance indicators was lost... I still don't have a single screen that shows me these key indicators" suggested that was not the case. Based on the volume and richness of Case 4's interview responses, their scale values received less weight in success assessment than in the other cases.

Costs. Costs with ERP implementation include not only software, but also items such as training, hardware, and consulting (Willis et al., 2001). The lack of a formal budget at some companies left them without the ability to compare actual versus budgeted costs, as described in the literature (e.g. Hong and Kim, 2002; Mabert et al., 2003b). Correspondingly, a relative measure of actual project cost as a percentage of annual revenue was used. The accounting manager at each company was asked to detail project costs in five categories (software, training, 
modifications, services, other), and to provide an estimate of annual revenue for the current year. This information was requested prior to the interview to facilitate data retrieval. Project cost was incorporated in the cross-case analysis of benefits so that if two companies achieved similar benefits but at different costs, the company that incurred the lower project costs (as $\%$ of annual revenue) was considered as relatively more successful.

Duration. Besides reviewing project documents, multiple participants at each company were asked for how long they had been using the new ERP. Triangulated values were always consistent. As the duration since going live increases, more categories of project benefits tend to be realized (Markus et al., 2000a; Hitt et al., 2002; McAfee, 2002; Gattiker and Goodhue, 2005; Weider et al., 2006,). For example, Gattiker and Goodhue (2005) found evidence of significant performance improvements over the first year after the implementation, and of continuous improvements (albeit at a decreasing rate) afterwards. Thus, in assessing ERP benefits, we included an additional item corresponding to the time elapsed since its implementation in the company. In other words, if two implementation projects obtained similar benefits but in different time lags, the company with a significantly shorter duration since going live would be considered relatively more successful.

Table III presents a summary assessment of project benefits, costs, and duration for each case. Implementation success was determined by the extent and nature of these variables as they were assessed in each company. This evaluation is detailed below.

Take in Table III 


\section{Implementation success}

Company 1 had been live on Software A for approximately two and a half years and actual project costs totaled just below $0.5 \%$ of annual sales. Operational benefits had not materialized, as inventory levels and delivery lead times were essentially unchanged. Administrative improvements were realized, e.g. office overtime was eliminated. Cash management benefits included a reduction in accounts receivable collection time. Managerial benefits resulted from improved access to information and improved efficiency in investigating specific transactions. On the IT side, system stability was similar to the legacy system, while costs were only slightly higher. Strategic benefits were limited to slightly improved customer service. Organizational benefits resulted as employees communicated with each other more. Employee morale improved slightly and was attributed to greater ability to complete tasks on time.

Company 2 had been live on Software A for approximately three years with actual project costs comprising approximately $0.4 \%$ of annual sales. Operational improvements directly attributable to the project had not materialized. However, substantial administrative improvements occurred to the point that employees requested more responsibilities, even as business volume increased. Cash management benefits included improvements in receivable collection and cash forecasting abilities. Managerial benefits included timely access to sales and financial performance indicators. IT system stability improved significantly from the legacy system, but costs were much higher. Strategic benefits included improved customer service and business growth support. Organizational benefits were mixed, as positive improvements in morale and empowerment at the head office were offset by branch employees being generally not pleased with the new system. 
Company 3 had been live on Software B for approximately one and a half years with actual project costs totaling about $2.9 \%$ of annual sales. Operationally, inaccurate inventory data and planning led to increased inventories and frequent order expediting. On the administrative side, staff felt they had to start completing tasks providing limited customer service or value. Minor cash management improvements resulted from better visibility of future revenues. Managerial abilities were inhibited as the new system did not provide key performance data. IT stability improved somewhat, although costs were slightly higher. Overall, improvements in some areas were offset by problems in others. Organizational results were generally negative due to job security concerns and reduced morale attributed to the many project challenges.

Company 4 had been live on Software A for about one year. Project expenses totaled approximately $3.0 \%$ of annual sales. Operationally, inventory levels almost doubled soon after going live; however, benefits such as improved inventory analysis and cycle counting were realized a year later. A significant increase in administration cost was attributed to data input requirements. Cash management abilities were considered unchanged. Managerial results were negative, as the owner lost visibility of key performance indicators. IT stability improved but costs increased significantly. Strategic benefits such as supporting business growth and customer service were realized. Organizational benefits were negative in the first six months. Employee morale improved slightly after one year.

Company 5 had been live on Software B for approximately one year. Project costs represented approximately $1.5 \%$ of annual sales. Operational benefits included highlighting inventory shortages and aiding production planning. Administrative improvements were realized as data only had to be entered once, and the previous requirement of reconciling multiple systems was eliminated. Cash management benefits were attributed to improved accounts receivable 
visibility and detail. Managerial benefits resulted from the visibility of "live" sales data by region and order tracking, enabling more responsive decision making. System's stability was comparable to the stability of legacy systems, but costs increased significantly. As with cases 2 and 4, the system supported business growth and customer service. Employee morale and empowerment were also improved.

\section{Results and Discussion}

Research findings are presented and discussed in two categories. First, we review the factors that appeared to clearly discriminate between successful and unsuccessful implementations across the

five cases. Next, we present distinctive factors that, although they could not explain variance in implementation success, appeared to be innovative or run counter to knowledge available from the literature; contrary to factors in the first category, these appeared to be unique to the SME context.

\section{Critical success factors}

Table IV presents an overview of the cross-case analysis leading to the identification of critical factors. The critical factors that emerged from this analysis are described next. The factors are summarized in Table V.

\section{Take in Table IV}

\section{Take in Table $V$}

Operational process discipline. The concept of process discipline has been formalized by Collins and Schmenner (1993) and Collins et al. (1998). In our study, companies were asked about documentation and consistency in executing operational processes (i.e. information flows) prior to the implementation. Companies having greater consistency prior to implementation 
appeared to achieve more successful implementations regardless of the level of documentation. The two unsuccessful cases had good documentation, but low discipline in adhering to standards set in documents. For example, Company 4 cited ISO audits that revealed non-conformance in sales and engineering. Company 3's poor record led to problems such as excess procurement to buffer for inaccurate inventory data; as the Accounting Manager indicated, "We were a custom job shop with 'craftsmen' who would each do things a little differently. The BOMs [bills of materials] were 'loose' and standard routings were non-existent... it was very dysfunctional." Consequently, both companies had difficulty adhering to processes that were newly developed by the ERP.

Overall, it seems that having inconsistent operational processes conflicts with the procedural rigidity of ERPs. Where such inconsistency exists, it may be necessary to carry out some process benchmarking and improvement prior to enforcing standardized procedures brought in by the ERP. This finding looks consistent with Schniederjans and Kim's (2003) conclusion (from a large company survey) that best implementations involve reengineering processes before rather than after the ERP introduction. Ross and Vitale (2000) similarly stated that ERP implementations posed challenges as they "... were instilling discipline into relatively undisciplined organizations.” (p. 240).

Thus, it appears that operational process discipline should be identified as a major CSF for ERP introduction at SMEs, especially given their frequently informal type of environment.

Small internal team. Successful companies had implementation teams that were smaller in size than the teams at unsuccessful companies. Four factors might explain the apparent lack of effectiveness or larger teams. First, larger teams tended to stay more isolated, as the impression of having complete horizontal expertise appeared to limit their interest in asking for input from 
outside users. In contrast, smaller teams sought user assistance regularly as they lacked expertise in certain areas. Company 2's Operations Manager suggested this was the major reason behind the team's success. Conversely, a team member from Company 4 described how isolation of their large team caused problems later on:

The implementation team [we] made decisions based on our team discussions. The team was comprised of the main user of each department. Some conflict resulted after going live with the end users - for example, engineering staff wanted more specific fields in the system, and felt the system was not doing what they wanted. The implementation team thought we had all the answers.

Second, larger teams had more difficulty in reaching consensus, and at times had conflicts among department representatives. Smaller teams would be more able to focus and compromise on what seemed best for the organization. Third, each of the two larger teams had at least one unreliable member that did not complete tasks, which negatively affected the project. The smaller teams suggested that a "sense of ownership" helped to give priority to project tasks whenever possible. Finally, larger teams appeared more difficult to manage by either the external consultant or the internal leader, which increased coordination costs.

In summary, it appears that using larger teams based on representation from each department was negatively associated with implementation time, quality, and cost at SMEs. Companies appeared to be better off by employing a smaller team that interacted as needed with the other staff. This finding appears to be at least partially supported by the view in Akkermans and van Helden (2002), Gattiker (2002), and Poba-Nzaou et al. (2008) that end-user involvement is a CSF, although the issue of team size per se has apparently not been addressed in the past.

Project management capabilities. These capabilities involved documentation and leadership to plan and control project tasks, responsibilities, and deadlines. In the often chaotic environment of SMEs, formal documentation helped to ensure that tasks and deadlines were not missed. 
Interestingly, implementation success appeared to be directly associated to who was the project leader: companies having external consultants at the helm appeared to achieve greater success, as consultants often had more relevant project management experience than internal leaders. Even Company 5, whose internal leader had extensive project management experience, still outsourced this task due to the leader's inability to be relieved of regular responsibilities (as Accounting Manager) during the project.

Given that internal leaders often had to carry on with regular (functional) duties in parallel to the project, it did not look surprising that tasks such as project documenting might slip down their priority list, significantly affecting the project. For example, project documents obtained at Company 4 included brief (e.g. three lines) handwritten minutes with no conclusions, dates, or responsibilities. Their Project Leader explained that, "the consultant helped us with setting up the checklist of tasks to do, but the ongoing administration (typing meeting minutes, to do's, etc.) was all done by internal staff." Moreover, they appeared to have no more than three project meetings over a three month period (some six months before the live date). In turn, companies 2 and 5 had extensive project documentation including tasks, responsibilities, and target dates, besides minutes of project decisions that were used as reference by the implementation team. Company 5's Project Leader illustrated this process:

We used MS Project and had a schedule with responsibilities, target dates, etc. We also had weekly progress meetings where we tracked our progress. It was primarily handled by the consultants. I worked closely with them - although they did the administration part of the project management, most of the details came from myself.

Formal project management has been similarly identified as CSF in previous research (e.g. Somers and Nelson, 2001; Zhang et al., 2003), though it has not been addressed whether it should be externally or internally managed. One exception might be Soja (2006), who found that a 
"detailed schedule" was only influential at large organizations; still, he appeared to be focusing on initial rather than ongoing scheduling.

In conclusion, the findings suggested that SME success with ERP implementations appeared to be associated to (i) assigning project management responsibility to the external consultant, and (ii) continually reviewing and revising documents during the implementation.

External end user training. We defined training as software specific instruction, and education as general skill-upgrading. Cross-case analysis initially revealed no significant variation in training (since all companies conducted some user training) or education (as only one successful and one unsuccessful company included relevant post-secondary education in the project). However, further investigation indicated that success might be associated to whether end user training was provided by an internal team member or an external consultant: the two unsuccessful companies used mostly the internal team; the three successful cases used an external consultant. As discussed above, it seems that the internal members lacked time and expertise to prepare and deliver training at the level required for the project.

Company 2's end user training (including at branch locations) was conducted by the consultant. The consultant was able to tailor the instruction based on business knowledge acquired by working with the internal team. According to the Project Leader (and consistent with findings in Chen et al. [2008]), combining the consultant's pedagogical expertise with business knowledge was critical. Conversely, Company 3 tasked team members with preparing and conducting training; despite their business experience, their approach was less than effective, as described by the Project Leader:

Each 'core analyst' prepared the training documents for their department. This resulted in a wide range of quality and detail - the SCM (Supply Chain Management) area refused to 
prepare manuals. Our staff were trained on how to do their daily jobs on the new system, but it was not in-depth enough. For example, some staff had one day of training three weeks before we went live, and production staff got about a four-hour overview. It was too much too quickly for the staff and a lot of it went right by them.

For some companies, one helpful aspect was that the internal team included most end users. As long as they received effective training from the consultant, the remaining learning could be carried out on the job. As explained by Company 5's Project Leader, "We did not do a large amount of training outside the implementation team. After we went live it was a 'show as you go' approach. This worked because the ratio of trained to untrained was low."

Previous studies emphasized the importance of training (Mabert et al., 2003b; Nah and Delgado, 2006; Finney and Corbett, 2007) and education (Muscatello et al., 2003). What we found was that SMEs might particularly benefit by end user training that was conducted by an external consultant due to lack of expertise or time of internal team members.

Management support. Interviewees independently identified factors that they associated with management support. Financial backing, encouragement, and alleviating team members from regular responsibilities were the most common themes. As with previous CSFs, we found clear differences between successful and unsuccessful companies regarding those items. Management support appeared particularly relevant due to their high level of involvement in SME routines, besides their direct influence on resource allocation and informal communication.

Financial support was often defined in terms of adequate funding for consulting and training. SMEs typically lacked technical expertise, thus the importance of such funding became clear. Despite that, management at Company 4 still balked at the cost of a quality consultant; instead they hired a lower cost independent consultant that had minimal experience with the new ERP. According to their Project Leader: "Looking back, I think it was a mistake to use an independent 
consultant that did not know the software. Financially the route we took was cheaper than paying the re-seller's hourly rates, but from an operational standpoint, it was a bad decision."

The second aspect was encouraging staff towards the implementation, which included management actions such as informal "championing" and attending to project meetings. Compare the differences between companies 5 and 3:

One employee, who was the master of the old system, thought the old system was better and had to be brought back in line. He was sharing his negative feelings towards the new software with staff and that affects staff productivity. I would not describe it as actively 'sabotaging' the project, but if it were not for upper management's support of the new system we probably would have ended up with a hybrid of the new system and the old system. (Project Leader, Company 5)

Management was not unified in support of the project. Some managers tried to subvert the project, which was difficult to overcome. Implementation team members got behind on their tasks because their managers were not supporting the project and providing them time for their implementation responsibilities. (CEO, Company 3 )

Perhaps the third aspect (alleviating team members from regular responsibilities) had a more subjective than objective effect. All three successful companies hired temporary employees to cover for project team members. Yet, in all cases the temporary staff left the company by the beginning of the implementation, resulting in no significant reduction in team members functional responsibilities. Nevertheless, team members were still positively impacted by management's sheer gesture to support their time in the project, regardless of the actual results.

Previous studies (e.g. Mabert et al., 2003b; Muscatello et al., 2003; Umble et al. 2003; Nah and Delgado, 2006) similarly stressed the importance of management support through the ERP implementation. This might be particularly relevant in SMEs due to their close-knit work environment. Surprisingly though, Soja (2006) indicated that that this factor might be significant only at large organizations. 
Qualified consultant. Project success appeared to be directly associated to the quality of the consultant. For example, interviewees stated that project teams relied heavily on external consultants because teams lacked software expertise and time. As described by Company 5's Project Leader: "I think the consultants are even more important than the internal team, especially in this environment. How can you build a strong internal team when there could be as few as one person with ERP experience - that is not a realistic expectation."

Interviewees assessed the quality of a consultant by attributes including business understanding, software knowledge, and soft skills. Concerning the first two aspects, consultants should be able to match business process and software capabilities, and were expected to be conversant not just in one module but in the whole software package. The third aspect was often judged as even more important, given the above mentioned close-knit environment of SMEs, as illustrated by a team member from Company 4 :

The consultant's 'soft skills' were terrible. He was condescending and would talk down to the team. It got to the point where you did not want to talk with him, so you just tried to solve things on your own, which is dangerous in this type of system. I think of the three that soft skills are the most important to have in a consultant for this type of project. If you don't want to interact with the consultant, it doesn't matter how good their business or software understanding is.

A consultant's relationship to success did not appear to be as prominent in previous studies. For example, "use of consultants" was rated lowest among 22 CSFs in Somers and Nelson (2001). This perhaps might be explained by respondents mixing the external consultant and the internal project team into one single factor. However, other studies (Al-Mashari et al., 2003; Finney and Corbett, 2007; Chen et al., 2008; Newman and Zhao, 2008) similarly stressed the importance of this factor. Furthermore, the skills that defined a quality consultant in our study appear to match ideas in Bingi et al. (1999), and the finding in Laukkanen et al. (2007) that small companies often have limited knowledge to guarantee successful ERP implementations. 


\section{Distinctive factors}

The following factors (summarized in Table VI) did not appear to explain success variance across the five studies. However, because of their innovative or counter-intuitive nature, they appeared to provide additional insight into the issues associated to ERP implementation in the SME cases.

\section{Take in Table VI}

Part-time dedication. The literature suggests that the internal team should be dedicated to the project full-time, away from everyday operations (Shanks et al., 2000; Mabert et al., 2003b; Umble et al., 2003). However, team members in the cases (including the project leader) were generally expected to carry on with functional tasks during the implementation. Moreover, that practice did not appear negatively associated to project success. One of the explanations for this counter-intuitive finding might come from the "hard-working" culture of the SMEs, as employees were expected to be flexible and take on additional responsibilities as needed. Consider for example Company 5 CEO's view: "Due to the size of our firm, we made it very clear that this project was over and above their regular duties and that we expected them to do whatever it takes, such as overtime and working weekends." Soja (2006) similarly found that "work time schedule" (i.e. time exclusively dedicated to the project) did not significantly influence success at SMEs (as opposed to large organizations).

Lack of formal communication. Previous studies (e.g. Mabert et al., 2003b; Mandal and Gunasekaran, 2003, Nah and Delgado, 2006) suggested that stakeholders should be provided with a detailed implementation plan including target business objectives, and should be kept informed about project progress. Concurring with Soja (2006), however, we found that in SMEs this might not be necessary. All of the successful cases appeared to place minimal or no effort towards formal communication, but no implementation challenges could be directly associated 
with that decision. Conversely, Company 3's extensive communication (e.g. placing posters on project progress throughout the facility) did not seem to particularly aid the implementation.

What did seem to influence success was the ability to "interact" (i.e. two-way) with staff to obtain their input and feedback. As explained by a team member from Company 2, "Communication on the project's progress to staff is not as important as letting them know time frames of go live and dates that they are needed for the project. The weekly project meeting minutes are not important for general staff. Communicating with them regarding their requirements is much more important."

Software modification. Achieving a proper fit between processes and software has been considered critical for ERP success (Fan et al., 2000; Gattiker, 2002; Bendoly and Jacobs, 2004; Quiescenti et al., 2006; Poba-Nzaou et al., 2008). Soh et al. (2000) and Gattiker and Goodhue (2002), among others, stated that such fitting could be achieved by either modifying processes to align with software or customizing software to align with processes.

In our study, all companies except Company 5 chose to significantly modify their software, including two successful and two unsuccessful companies. This was somewhat surprising because of the limited resources and IT skills available to the SME companies. Inevitably, all of the four companies faced additional challenges in testing and simply understanding how the software operated after the modifications. As stated by a team member from Company 1, "Where we had those software problems of fixing one thing and unfixing another - we thought the two things were totally unrelated. We would not even have thought of testing it."

It appears that SMEs chose to adapt software to processes rather than vice-versa to avoid failures in processes that were considered either strategic or reliable before the implementation. The downside was that software integration and testing turned more difficult as staff lacked time 
and technical expertise, and external consultants often lacked business-specific knowledge. The only approach that would appear satisfactory would be gathering the internal team and consultants to test the software together rather than assigning this responsibility to a single party.

Informal strategy. Contrary to expectations, at two of the three successful cases the business strategy was not formalized or communicated to the team. Project decisions were based on current business requirements and expected growth. This approach appeared to have a short-term focus, yet over two and a half and three years later respectively, both companies 1 and 2 were still experiencing significant benefits from the project. This would suggest that SMEs might achieve project success despite a lack of formal strategy. Soja (2006) similarly found that "linking with strategy" and "implementation goals" were not significant factors at SMEs. This seems to be opposed to findings from large organization studies (Stratman and Roth, 2002; AlMashari et al., 2003; Umble et al., 2003) that identified strategic visioning or planning as a CSF. Other authors have stressed the informal nature of SMEs (Mintzberg et al., 2003, p. 217) and their lack of proactive planning (Gunasekaran et al., 1996).

At least two hypotheses might explain the seemingly absent relationship between strategy formalization and performance. First, legacy systems might be so inadequate that improvements were obtained despite the strategic alignment. Second, SME staff might be tacitly aware of the strategic vision to incorporate this vision into project plans.

\section{Conclusion}

This study explored CSFs of ERP implementation at five Canadian SMEs. It provided three main contributions. First, as discussed earlier, while many studies have explored ERP implementations in large organizations, fewer have focused on SMEs. Muscatello et al. (2003) focused on subsidiaries of large firms. Loh and Koh (2004) interviewed eight British SMEs on ERP CSFs, 
"critical people" and "critical uncertainties"; however, findings regarding CSFs in particular appeared to be mainly based on literature review. Since there is strong evidence that SMEs operate differently from large organizations, our study provided specific direction to SME managers contemplating ERP implementation. This was done by identifying six factors (Tables IV and V) that were considered critical to ERP implementation success in the SMEs under study. Companies that managed these issues effectively had higher probability of implementation success. Further, we identified four distinctive factors (Table VI) that SME managers would need to be cognizant of when implementing ERP.

Second, our methodology of in-depth interviews with company personnel provided insightful details to the factors that were influential in project success, which previous studies might not have been able to provide. For example, our study clearly showed that operations process discipline was a CSF at SMEs, but what does it mean in practice? Through the interviews, we could identify that it consisted of aspects such as the need for standardized routings and bills of materials. Such detailed insights extend to our distinctive factors as well. For instance, both successful and unsuccessful companies had modified their software, thus making it unclear whether such modification could be considered a CSF. However, the study detailed the problems involved in this modification, i.e. that software integration and testing became a challenge due to the lack of technical expertise on the part of the staff and the lack of business expertise on the part of the external consultant. Thus, the findings point to the need for implementations to ensure that both technical and business expertise is integrated during software testing.

Third, in relating our research to previous studies, it seems that some of our findings appeared to concur with the literature, but others appeared to be either innovative or counter to existing knowledge. In particular, our findings confirm that factors such as process discipline, 
management support, and a qualified consultant with strong soft skills were important to ERP implementation success at SMEs. Our findings concurred with previous studies that both project management and end user training might be considered CSFs, however we further characterized their nature in the SME environment. For example, given that the internal team had regular responsibilities during the implementation, it appeared critical that the external consultant managed the project and conducted end user training. Furthermore, our findings extend the knowledge about user involvement (which was similarly identified in previous studies), suggesting that it might be enhanced by the use of a small rather than large internal team. Furthermore, findings including the success with part-time dedication of project staff, lack of formal communication, emphasis on software (rather than process) modification, and the lack of formal strategy processes appeared to be somehow counter-intuitive. These findings provide additional insight into the issues involved in managing ERP implementations at SMEs.

As with other qualitative research, this study has limitations that might constrain the generalizability or validity of findings. The research was based on five Canadian SMEs and thus its results might not be generalizable to other countries. Chien et al. (2007) suggested that macroeconomic factors across geographic locations had no significant influence on ERP success; Newman and Zhao (2008) suggested that "culture" did not play a significant role either. However, other studies indicated that country differences might influence aspects of ERP implementation and usage (Sheu et al., 2004) and performance (Ragowsky et al., 2000). Thus, there is an opportunity for replicating this study across different countries or regions. Second, the research focused on manufacturing and distribution companies and thus findings might be not generalizable to service industries. Third, even though we specifically collected data about implementation, its benefits and challenges, some of these benefits and challenges could still be 
attributable to efforts to improve their ERP system long after the implementation, as pointed out by Gattiker and Goodhue (2005). Finally, our research was based on interviews that occurred from one to three years after implementation. Under these circumstances, participants might have limited or inaccurate memory. Although triangulation methods were employed including interviewing a cross-section of project participants and incorporating project documents, a longitudinal study observing an implementation project right from its start could have provided more extensive information about the project motivation, implementation, and results.

The primary research implication concerns the need to carry out process improvement and technology studies that focus on SMEs, as they perform a significant role in major economies. In addition, the use of case studies can provide valuable detail and insight into such a complex subject. For practitioners, our study indicates that implementing ERPs at SMEs can provide significant benefits if some critical practices are in place. Such factors should aid to prioritize implementation efforts and resources, and maximize the chances of success.

Our study could not directly compare the CSFs identified in previous studies based on large organizations and the CSFs identified by us in this study on SMEs. This resulted from our focus on a few companies. So, our results may not be sufficiently general to compare it previous studies based primarily on large surveys. However, as noted earlier, our research does enhance the understanding of the nature of ERP implementation in SMEs. As illustrated by our discussion that included quotes from managers, we were able to provide some insights into the complex nature of ERP implementations that surveys perhaps could not have. Future research could involve a survey study that includes both large organizations and SMEs. This would allow a statistically valid comparison of CSFs between both types of organizations. 


\section{References}

Achanga, P.; Shehab, E.; Roy, R. and Nelder, G. (2006), "Critical success factors for lean implementation within SMEs", Journal of Manufacturing Technology Management, Vol. 17 No. 4, pp. 460-71.

Adam, F. and O’Doherty, P. (2000), “Lessons from enterprise resource planning implementations in Ireland - towards smaller and shorter ERP projects", Journal of Information Technology, Vol. 15 No. 4, pp. 305-16.

Akkermans, H. and van Helden, K. (2002), "Vicious and virtuous cycles in ERP implementation: a case study of interrelations between critical success factors", European Journal of Information Systems, Vol. 11 No. 1, pp. 35-46.

Al-Mashari, M.; Al-Mudimigh, A. and Zairi, M. (2003), "Enterprise resource planning: a taxonomy of critical factors”, European Journal of Operational Research, Vol. 146 No. 2, pp. 352-64.

Ash, C. G. and Burn, J.M. (2003), “A strategic framework for the management of ERP enabled ebusiness change", European Journal of Operational Research, Vol. 146 No. 2, pp. 374-87.

Bell, S. and Orzen, M. (2007), “Small, yet mighty”, APICS Magazine, Vol. 17 No. 6, pp. 40-3.

Bendoly, E. and Jacobs, F.R. (2004), "ERP architectural/operational alignment for orderprocessing performance", International Journal of Operations and Production Management, Vol. 24 No. 1, pp. 99-117.

Bernroider, E. and Koch, S. (2001), "ERP selection process in midsized and large organizations", Business Process Management Journal, Vol. 7 No. 3, pp. 251-7. 
Bingi, P.; Sharma, M.K. and Godla, J. (1999), "Critical issues affecting an ERP implementation”, Information Systems Management, Vol. 16 No. 3, pp. 7-14.

Buonanno, G., Faverio, P., Pigni, F., Ravarini, A., Sciuto, D. and Tagliavini, M. (2005), "Factors affecting ERP system adoption: A comparative analysis between SMEs and large companies", Journal of Enterprise Information Management, Vol. 18 No. 4, pp. 384-426.

Chen, R., Sun, C., Helms, M.M. and Jih, W. (2008), "Role negotiation and interaction: an exploratory case study of the impact of management consultants on ERP system implementation in SMEs in Taiwan”, Information Systems Management, Vol. 25 No. 2, pp. $159-73$.

Chien, S.; Hu, C.; Reimers, K. and Lin, J. (2007), "The influence of centrifugal and centripetal forces on ERP project success in small and medium-sized enterprises in China and Taiwan", International Journal of Production Economics, Vol. 107 No. 2, pp. 380-96.

Collins, R.S. and Schmenner, R.W. (1993), “Achieving rigid flexibility: factory focus for the 1990s”, European Management Journal, Vol.11 No.4, pp. 443-7.

Collins, R.S., Cordon, C. and Julien, D. (1998), “An empirical test of the rigid flexibility model”, Journal of Operations Management, Vol.16 No.2/3, pp. 133-46.

Davenport, T.H. (1998), "Putting the enterprise into the enterprise system", Harvard Business Review, Vol. 76 No. 4, pp. 121-31.

Deep, A., Guttridge, P., Dani, S. and Burns, N. (2008), "Investigating factors affecting ERP selection in made-to-order SME sector", Journal of Manufacturing Technology Management, Vol. 19 No. 4, pp. 430-46. 
Eisenhardt, K.M. (1989), "Building theories from case study research”, Academy of Management Review, Vol. 14 No. 4, pp. 532-50.

Eshelman, R.G., Juras, P.E. and Taylor, T.C. (2001), "When SMALL COMPANIES implement...BIG SYSTEMS", Strategic Finance, Vol. 82 No. 8, pp. 28-33.

Esteves-Souza, J. and Pastor-Collado, J. (2000), "Towards the unification of critical success factors for ERP implementations", Proceedings of the 10th Annual Business Information Technology (BIT) Conference, Manchester, 9 pp.

Eurostat (2007), "European business - 2006 edition - chapter 1: business economy overview", available from http://epp.eurostat.ec.europa.eu/cache/ITY_OFFPUB/KS-BW-06-00101/EN/KS-BW-06-001-01-EN.PDF. Accessed on June 22, 2008.

Fan, M.; Stallaert, J. and Whinston, A. (2000), "The adoption and design methodologies of component-based enterprise systems", European Journal of Information Systems, Vol. 9 No. 1, pp. 25-35.

Finney, S. and Corbett, M. (2007), "ERP implementation: a compilation and analysis of critical success factors", Business Process Management Journal, Vol. 13 No. 3, pp. 329-47.

Gattiker, T.F. (2002), "Anatomy of an ERP implementation gone awry", Production and Inventory Management Journal, Vol. 43 No. 3/4, pp. 96-105.

Gattiker, T.F. and Goodhue, D.L. (2002), "Software driven changes to business processes: an empirical study of impacts of Enterprise Resource Planning (ERP) systems at the local level”, International Journal of Production Research, Vol. 40 No. 18, pp. 4799-814. 
Gattiker, T.F. and Goodhue, D.L. (2005), "What happens after ERP implementation: understanding the impact of interdependence and differentiation on plant-level outcomes", MIS Quarterly, Vol. 29 No. 3, pp. 559-85.

Ghobadian, A. and Gallear, D.N. (1996), “Total quality management in SMEs”, Omega, Vol. 24 No. 1, pp. 83-106.

Gunasekaran, A.; Okko, P.; Martikainen, T. and Yli-Olli, P. (1996), "Improving productivity and quality in small and medium enterprises: cases and analysis", International Small Business Journal, Vol. 15 No. 1, pp. 59-72.

Herzog, T. (1996), Research Methods in the Social Sciences, Prentice-Hall, Upper Saddle River, NJ.

Hillebrand, B.; Kok, R.A.K. and Biemans, W.G. (2001), "Theory-testing using case studies: a comment on Johnston, Leach, and Liu", Industrial Marketing Management, Vol. 30 No. 8, pp. 651-7.

Hitt, L.M.; Wu, D.J. and Zhou, X. (2002), “Investment in enterprise resource planning: business impact and productivity measures”, Journal of Management Information Systems, Vol. 19 No. 1, pp. 71-98.

Hong, K.-K. and Kim, Y.-G. (2002), “The critical success factors for ERP implementation: an organizational fit perspective", Information and Management, Vol. 40 No. 1, pp. 25-40.

Huin, S.F. (2004), "Managing deployment of ERP systems in SMEs using multi-agents", International Journal of Project Management, Vol. 22 No. 6, pp. 511-17. 
Huin, S.F.; Luong, L.H.S. and Abhary, K. (2003), "Knowledge-based tool for planning of enterprise resources in ASEAN SMEs", Robotics and Computer-Integrated Manufacturing, Vol. 19 No. 5, pp. 409-14.

Industry Canada (2006), "Key small business statistics - July 2006”, available from http://strategis.ic.gc.ca/epic/site/sbrp-rppe.nsf/en/rd02030e.html. Accessed on June 22, 2008.

Jacobs, F.R. and Bendoly, E. (2003), “Enterprise resource planning: developments and directions for operations management research”, European Journal of Operational Research, Vol. 146 No. 2, pp. 233-40.

Jacobs, F.R. and Weston Jr., F.C. (2007), "Enterprise resource planning (ERP) - A brief history”, Journal of Operations Management, Vol. 25 No. 2, pp. 357-63.

Jones, M.C. and Young, R. (2006), "ERP usage in practice: an empirical investigation', Information Resources Management Journal, Vol. 19 No. 1, pp. 23-42.

Kinni, B.T. (1995), “Process improvement, part 2”, Industry Week, Vol. 244 No. 4, pp. 45-50.

Kumar, V.; Maheshwari, B. and Kumar, U. (2002), "Enterprise resource planning systems adoption process: a survey of Canadian organizations", International Journal of Production Research, Vol. 40 No. 3, pp. 509-23.

Laukkanen, S., Sarpola, S. and Hallikainen, P. (2007), "Enterprise size matters: objectives and constraints of ERP adoption”, Journal of Enterprise Information Management, Vol. 20 No. 3, pp. 319-34. 
Lee, G.L. and Oakes, I. (1995), “The 'pros' and 'cons' of total quality management for smaller firms in manufacturing: some experiences down the supply chain”, Total Quality Management, Vol. 6 No. 4, pp. 413-26.

Loh, T.C. and Koh, S.C.L. (2004), "Critical elements for a successful enterprise resource planning implementation in small-and medium-sized enterprises", International Journal of Production Research, Vol. 42 No. 17, pp. 3433-55.

Lu, C.-C. (2006), "Growth strategies and merger patterns among small and medium-sized enterprises: an empirical study", International Journal of Management, Vol. 23 No. 3, pp. $529-47$.

Mabert, V.A.; Soni, A. and Venkataramanan, M.A. (2000), "Enterprise resource planning survey of U.S. manufacturing firms", Production and Inventory Management Journal, Vol. 41 No. 2, pp. 52-8.

Mabert, V.A.; Soni, A. and Venkataramanan, M.A. (2003a), "The impact of organization size on enterprise resource planning (ERP) implementations in the US manufacturing sector", Omega, Vol. 31 No. 3, pp. 235-46.

Mabert, V.A.; Soni, A. and Venkataramanan, M.A. (2003b), "Enterprise resource planning: managing the implementation process", European Journal of Operational Research, Vol. 146 No. 2, pp. 302-14.

Mandal, P. and Gunasekaran, A. (2003), "Issues in implementing ERP: a case study", European Journal of Operational Research, Vol. 146 No. 2, pp. 274-83. 
Markus, M.L.; Axline, S.; Petrie, D. and Tanis, C. (2000a), “Learning from adopters' experiences with ERP: problems encountered and success achieved", Journal of Information Technology, Vol. 15 No. 4, pp. 245-65.

Markus, M.L.; Tanis, C. and van Fenema, P.C. (2000b), "Multisite ERP implementations", Communications of the ACM, Vol. 43 No. 4, pp. 42-6.

McAdam, R. (2000), “Quality models in an SME context: a critical perspective using a grounded approach", International Journal of Quality and Reliability Management, Vol. 17 No. 3, pp. $305-23$.

McAdam, R. (2002), "Large scale innovation - reengineering methodology in SMEs: positivistic and phenomenological approaches”, International Small Business Journal, Vol. 20 No. 1, pp. $33-50$

McAfee, A. (2002), "The impact of enterprise technology adoption on operational performance: an empirical investigation", Production and Operations Management, Vol. 11 No. 1, pp. 3353.

McCartan-Quinn, D. and Carson, D. (2003), "Issues which impact upon marketing in the small firm”, Small Business Economics, Vol. 21 No. 2, pp. 201-13.

Meredith, J. (1998), "Building operations management theory through case and field research", Journal of Operations Management, Vol. 16 No. 4, pp. 441-54.

Miles, M.B. and Huberman, A.M. (1994), Qualitative Data Analysis: An Expanded Sourcebook, Sage, London. 
Mintzberg, M.; Lampel, J.; Quinn, J.B. and Ghosal, S. (2003), The Strategy Process: Concepts Contexts Cases, Upper Saddle River, NJ: Prentice Hall.

Morris, M.W.; Leung, K.; Ames, D. and Lickel, B. (1999). "Views from inside and outside: integrating emic and etic insights about culture and justice judgment", Academy of Management Review, Vol. 24 No. 4, pp. 781-96.

Muscatello, J.R.; Small, M.H. and Chen, I.C. (2003), "Implementing enterprise resource planning (ERP) systems in small and midsize manufacturing firms", International Journal of Operations and Production Management, Vol. 23 No. 8, pp. 850-71.

Nah, F.F.-H. and Delgado, S. (2006), "Critical success factors for enterprise resource planning implementation and upgrade", Journal of Computer Information Systems, Vol. 46 No. 5, pp. 99-113.

Nah, F.F.-H.; Zuckweiler, K.M. and Lau, J.L.-S. (2003), "ERP implementation: Chief Information Officers' perceptions of critical success factors", International Journal of Human-Computer Interaction, Vol. 16 No. 1, pp. 5-22.

Newman, M. and Zhao, Y. (2008), “The process of enterprise resource planning implementation and business process re-engineering: tales from two Chinese small and medium-sized enterprises", Information Systems Journal, Vol. 18 No. 4, pp. 405-26.

Olhager, J. and Selldin, E. (2003), "Enterprise resource planning survey of Swedish manufacturing firms", European Journal of Operational Research, Vol. 146 No. 2, pp. 36573.

Patton, M.Q. (1987), How to Use Qualitative Methods in Evaluation, Sage, Beverly Hills, CA. 
Pettigrew, A.M. (1990), "Longitudinal field research on change: theory and practice", Organization Science, Vol. 1 No. 3, pp. 267-92.

Poba-Nzaou, P., Raymond, L. and Fabi, B. (2008), “Adoption and risk of ERP systems in manufacturing SMEs: a positivist case study", Business Process Management Journal, Vol. 14 No. 4, pp. 530-50.

Quiescenti, M., Bruccoleri, M., La Commare, U., Noto La Diega, S. and Perrone, G. (2006), "Business process-oriented design of enterprise resource planning (ERP) systems for small and medium enterprises", International Journal of Production Research, Vol. 44 No. 18/19, pp. 3797-811.

Ragowsky, A.; Stern, M. and Adams, D.A. (2000), "Relating benefits from using IS to an organization's operating characteristics: interpreting results from two countries", Journal of Management Information Systems, Vol. 16 No. 4, pp. 175-94.

Rao, S.S. (2000), "Enterprise resource planning: business needs and technologies", Industrial Management and Data Systems, Vol. 100 No. 2, pp. 81-8.

Raymond, L. and Uwizeyemungu, S. (2007), "A profile of ERP adoption in manufacturing SMEs", Journal of Enterprise Information Management, Vol. 20 No. 4, pp. 487-502.

Raymond, L.; Bergeron, F. and Rivard, S. (1998), "Determinants of business process reengineering success in small and large enterprises: an empirical study in the Canadian context", Journal of Small Business Management, Vol. 36 No. 1, pp. 72-85.

Robey, D.; Ross, J.W. and Boudreau, M.-C. (2002), "Learning to implement enterprise systems: an exploratory study of the dialectics of change", Journal of Management Information Systems, Vol. 19 No. 1, 17-46. 
Ross, J. W. and Vitale, M., (2000). “The ERP revolution: Surviving versus thriving”, Information Systems Frontiers, Vol. 2, No. 2, pp. 233-41.

Sapsford, R. and Jupp, V. (1996), Data Collection and Analysis, Sage, London.

Schniederjans, M.J. and Kim, G.C. (2003), "Implementing enterprise resource planning systems with total quality control and business process reengineering: survey results", International Journal of Operations and Production Management, Vol. 23 No. 4, pp. 418-29.

Serafeimidis, V. and Smithson, S. (1999), "Rethinking the approaches to information systems investment evaluation”, Logistics Information Management, Vol. 12 no. 1/2, pp. 94-107.

Shang, S. and Seddon, P.B. (2000), "A comprehensive framework for classifying the benefits of ERP systems", Proceedings of the Sixth Americas Conference on Information Systems, Long Beach, pp. 1005-14.

Shanks, G.; Parr, A.; Hu, B.; Corbitt, B.; Thanasankit, T. and Seddon, P. (2000), "Differences in critical success factors in ERP systems implementation in Australia and China: a cultural analysis", Proceedings of the Eighth European Conference on Information Systems, Vienna, pp. 537-44.

Sheu, C.; Chae, B. and Yang, C.-L. (2004), "National differences and ERP implementation: issues and challenges", Omega, Vol. 32 No. 5, pp. 361-71.

Shin, I. (2006), "Adoption of enterprise application software and firm performance", Small Business Economics, Vol. 26 No. 3, pp. 241-56.

Soh, C.; Kien, S.S. and Tay-Yap, J. (2000), "Cultural fits and misfits: is ERP a universal solution?", Communications of the ACM, Vol. 43 No. 4, pp. 47-51. 
Soja, P. (2006), "Success factors in ERP systems implementations: lessons from practice", Journal of Enterprise Information Management, Vol. 19 No. 4, pp. 418-33.

Somers, T.M. and Nelson, K. (2001), "The impact of critical success factors across the stages of enterprise resource planning implementations", Proceedings of the 34th Hawaii International Conference on Systems Sciences, Maui, 10 pp.

Stefanou, C.J. (2001), “A framework for the ex-ante evaluation of ERP software”, European Journal of Information Systems, Vol. 10 No. 4, pp. 204-15.

Stratman, J.K. and Roth, A.V. (2002), "Enterprise resource planning (ERP) competence constructs: two-stage multi-item scale development and validation", Decision Sciences, Vol. 33 No. 4, pp. 601-28.

Strauss, A. and Corbin, J. (1990), Basics of Qualitative Research: Grounded Theory Procedures and Techniques, Sage, Newbury Park, CA.

Stuart, I.; McCutcheon, D.; Handfield, R.; McLachlin, R. and Samson, D. (2002), "Effective case research in operations management: a process perspective", Journal of Operations Management, Vol. 20 No. 5, pp. 419-33.

Sun, A.Y.T.; Yazdani, A. and Overend, J.D. (2005), “Achievement assessment for enterprise resource planning (ERP) system implementations based on critical success factors (CSFs)", International Journal of Production Economics, Vol. 98 No. 2, pp. 189-203.

Umble, E.J.; Haft, R.R. and Umble, M.M. (2003), “Enterprise resource planning: implementation procedures and critical success factors", European Journal of Operational Research, Vol. 146 No. 2, pp. 241-57. 
US Census Bureau (2004), "Statistics about business size (including small business) from the U.S. Census Bureau", available from http://www.census.gov/epcd/www/smallbus.html. Accessed on June 22, 2008.

Van Everdingen, Y.; Van Hillegersberg, J. and Waarts, E. (2000), “ERP adoption by European midsize companies", Communications of the ACM, Vol. 43 No. 4, pp. 27-31.

Weber, R.P. (1990), Basic Content Analysis, Sage, Newbury Park, CA.

Weider, B.; Booth, P.; Matolcsy, Z.P. and Ossimitz, M.-L. (2006), “The impact of ERP systems on firm and business performance", Journal of Enterprise Information Management, Vol. 19 No. 1, pp. 13-29.

Willis, T.H.; Willis-Brown, A.H. and McMillan, A. (2001), "Cost containment strategies for ERP system implementations", Production and Inventory Management Journal, Vol. 42 No. 2, pp. $36-42$.

Yin, R.K. (1994), Case Study Research: Design and Methods, Sage, Thousand Oaks, CA.

Zhang, L.; Lee, M.K.O.; Zhang, Z. and Banerjee, P. (2003), "Critical success factors of enterprise resource planning systems implementation success in China”, Proceedings of 36th Hawaii International Conference on System Sciences, Big Island, HI, $10 \mathrm{pp}$. 
Table I. ERP critical success factors from the literature.

\begin{tabular}{|c|c|c|c|c|c|c|c|c|c|c|c|}
\hline & & $\operatorname{Im}$ & nen. & & & $\operatorname{Im}$ & hent & & & & $\begin{array}{c}\text { Post- } \\
\text { Implemen. }\end{array}$ \\
\hline Source & Method and Sample & $1^{1}$ & 2 & 3 & 4 & 5 & 6 & 7 & 8 & 9 & 10 \\
\hline Al-Mashari et al. (2003) & Literature Review & $\mathrm{X}$ & $\mathrm{X}$ & $\mathrm{X}$ & $\mathrm{X}$ & $\mathrm{X}$ & $\mathrm{X}$ & $\mathrm{X}$ & $\mathrm{X}$ & & $\mathrm{X}$ \\
\hline Ash and Burn (2003) & $\begin{array}{c}6 \text { case studies ( } 4 \text { in large } \\
\text { companies) }\end{array}$ & $X$ & $X$ & & & & & $X$ & $X$ & $X$ & \\
\hline $\begin{array}{l}\text { Esteves-Souza and Pastor- } \\
\text { Collado (2000) }\end{array}$ & Literature review & & & $\mathrm{X}$ & $\mathrm{X}$ & $X$ & $X$ & $X$ & $\mathrm{X}$ & $X$ & \\
\hline Finney and Corbett (2007) & Literature review & $\mathrm{X}$ & & $\mathrm{X}$ & $\mathrm{X}$ & $\mathrm{X}$ & $X$ & $\mathrm{X}$ & $\mathrm{X}$ & $\mathrm{X}$ & $\mathrm{X}$ \\
\hline Gattiker (2002) & Single case study & $X$ & $\mathrm{X}$ & $\mathrm{X}$ & $\mathrm{X}$ & & & & $\mathrm{X}$ & & \\
\hline Hong and Kim (2002) & $\begin{array}{c}34 \text { manufacturing and } \\
\text { service firms }(91 \% \text { with } \\
100+\text { staff })\end{array}$ & & $X$ & & & & & $\mathrm{X}$ & & & \\
\hline Loh and Koh (2004) & $\begin{array}{l}\text { Literature review and } \\
\text { interviews in } 8 \mathrm{UK} \text { SMEs }\end{array}$ & $X$ & & $\mathrm{X}$ & $\mathrm{X}$ & $\mathrm{X}$ & $X$ & $\mathrm{X}$ & & $X$ & $X$ \\
\hline Mabert et al. (2003b) & $\begin{array}{l}75 \text { US firms ( } 77 \% \text { with } \\
1000+\text { staff })\end{array}$ & & & $\mathrm{X}$ & $\mathrm{X}$ & & & & $\mathrm{X}$ & & \\
\hline Mandal and Gunasekaran (2003) & $\begin{array}{c}\text { Case study of a large } \\
\text { organization }\end{array}$ & & $\mathrm{X}$ & & $\mathrm{X}$ & & $X$ & $\mathrm{X}$ & $X$ & $X$ & $X$ \\
\hline Muscatello et al. (2003) & $\begin{array}{c}4 \text { case studies ( } \$ 55 M-\$ 200 M \\
\text { annual revenue) }\end{array}$ & $X$ & & $\mathrm{X}$ & & $\mathrm{X}$ & $X$ & & $\mathrm{X}$ & & \\
\hline Nah and Delgado (2006) & $\begin{array}{c}\text { Case studies of two large } \\
\text { organizations }\end{array}$ & $X$ & $\mathrm{X}$ & $\mathrm{X}$ & $\mathrm{X}$ & & $X$ & $\mathrm{X}$ & $\mathrm{X}$ & $X$ & \\
\hline Nah et al. (2003) & Literature review & & $\mathrm{X}$ & $\mathrm{X}$ & & $\mathrm{X}$ & $\mathrm{X}$ & $\mathrm{X}$ & & $\mathrm{X}$ & \\
\hline Soja (2006) & $\begin{array}{l}39 \text { firms (>300 staff }) \\
29 \text { firms (<300 staff })\end{array}$ & $X$ & $\mathrm{X}$ & $\mathrm{X}$ & & & $\mathrm{X}$ & & $X$ & $X$ & \\
\hline Somers and Nelson (2001) & $\begin{array}{c}86 \text { firms }^{2} \text { from various } \\
\text { industries }\end{array}$ & & $\mathrm{X}$ & $\mathrm{X}$ & $\mathrm{X}$ & $X$ & $\mathrm{X}$ & $\mathrm{X}$ & $X$ & $X$ & \\
\hline Stratman and Roth (2002) & $\begin{array}{l}79 \text { North American } \\
\text { manufacturers }\end{array}$ & $\mathrm{X}$ & & $\mathrm{X}$ & & & $\mathrm{X}$ & $\mathrm{X}$ & $X$ & & \\
\hline Umble et al. (2003) & $\begin{array}{l}\text { Case study of large } \\
\text { organization }\end{array}$ & $X$ & & $\mathrm{X}$ & & & $\mathrm{X}$ & $X$ & $X$ & $X$ & $X$ \\
\hline Zhang et al. (2003) & 47 Chinese firms & & $\mathrm{X}$ & $\mathrm{X}$ & & & $\mathrm{X}$ & & $\mathrm{X}$ & & \\
\hline
\end{tabular}

${ }^{1}$ CSFs: 1: Strategic visioning/planning; 2: organizational fit of ERP; 3: management support and involvement; 4: communication; 5: business process reengineering; 6: project management; 7: change management; 8: training and education; 9: internal implementation team; 10: performance evaluation. ${ }^{2}$ Drawn from Fortune 500 firms and Directory of Top Computer Executives 
Table II. Case study demographics.

\begin{tabular}{|c|c|c|c|c|c|}
\hline & Case 1 & Case 2 & Case 3 & Case 4 & Case 5 \\
\hline Industry & $\begin{array}{l}\text { Natural } \\
\text { resources }\end{array}$ & Chemicals & Electronics & Electronics & $\begin{array}{l}\text { Plumbing } \\
\text { and heating }\end{array}$ \\
\hline Company type & Distributor & $\begin{array}{c}\text { Manufacturer/ } \\
\text { distributor }\end{array}$ & Manufacturer & Manufacturer & Manufacturer \\
\hline Company size (employees) & Small & Medium & Medium & Small & Small \\
\hline Formal strategic planning & No & Somewhat & Yes & No & Yes \\
\hline Organization levels & 3 & $4-5$ & $4-7$ & 3 & 3 \\
\hline ERP software ${ }^{1}$ & A & A & B & A & B \\
\hline \# of user licenses & 10 & 40 & 100 & 17 & 12 \\
\hline
\end{tabular}

T"A" and "B" are used to disguise the actual software used 
Table III. Success evaluation.

\begin{tabular}{|c|c|c|c|c|c|c|}
\hline Benefits Realized & Questionnaire Item & Case 1 & Case 2 & Case 3 & Case 4 & Case 5 \\
\hline - Operational & $\begin{array}{l}\text { "Cost reductions, cycle time } \\
\text { reductions, inventory reductions" }\end{array}$ & Neutral & Neutral & Negative & Neutral & Positive \\
\hline - Administrative & $\begin{array}{l}\text { "Productivity improvements } \\
\text { (administration)" }\end{array}$ & Positive & Positive & Negative & Negative & Positive \\
\hline - Cash Management & $\begin{array}{l}\text { "Cash management } \\
\text { improvements" }\end{array}$ & Positive & Positive & Neutral & Neutral & Positive \\
\hline - Managerial & $\begin{array}{l}\text { Improved decision making } \\
\text { enabled by access to information }\end{array}$ & Positive & Positive & Negative & Negative & Positive \\
\hline - IT Stability & $\begin{array}{l}\text { "Stability of system, business } \\
\text { flexibility" }\end{array}$ & Neutral & Positive & Positive & Positive & Neutral \\
\hline - IT Costs & "Reduction in IT costs" & Neutral & Negative & Neutral & Negative & Negative \\
\hline - Strategic & $\begin{array}{l}\text { "Supporting business growth, } \\
\text { cost leadership, customers } \\
\text { service, linkages to customers" }\end{array}$ & Neutral & Positive & Neutral & Positive & Positive \\
\hline - Organizational & $\begin{array}{l}\text { "Supporting organizational } \\
\text { change, employee } \\
\text { empowerment, employee morale } \\
\text { and satisfaction, business } \\
\text { learning (integrating the } \\
\text { organization)" }\end{array}$ & Positive & Neutral & Negative & Neutral & Positive \\
\hline Project Cost & $\begin{array}{l}\% \text { of annual revenue } \\
\text { (adjustment) }\end{array}$ & $\begin{array}{c}0.5 \% \\
\text { (Positive) }\end{array}$ & $\begin{array}{c}0.4 \% \\
\text { (Positive) }\end{array}$ & $\begin{array}{c}2.9 \% \\
\text { (Negative) }\end{array}$ & $\begin{array}{c}3.0 \% \\
\text { (Negative) }\end{array}$ & $\begin{array}{c}1.5 \% \\
\text { (Neutral) }\end{array}$ \\
\hline Duration & $\begin{array}{l}\text { Years since live date } \\
\text { (adjustment) }\end{array}$ & $\begin{array}{c}2.5 \\
\text { (Negative) }\end{array}$ & $\begin{array}{c}3.0 \\
\text { (Negative) }\end{array}$ & $\begin{array}{c}1.5 \\
\text { (Neutral) }\end{array}$ & $\begin{array}{c}1.0 \\
\text { (Positive) }\end{array}$ & $\begin{array}{c}1.0 \\
\text { (Positive) }\end{array}$ \\
\hline Overall Assessment & & Successful & Successful & $\begin{array}{c}\text { Very } \\
\text { Unsuccessful }\end{array}$ & Unsuccessful & $\begin{array}{c}\text { Very } \\
\text { Successful }\end{array}$ \\
\hline
\end{tabular}


Table IV. Cross case analysis.

\begin{tabular}{|c|c|c|c|c|c|}
\hline & \multicolumn{3}{|c|}{ Successful Projects } & \multicolumn{2}{|c|}{ Unsuccessful Projects } \\
\hline & Case 1 & Case 2 & Case 5 & Case 3 & Case 4 \\
\hline \multicolumn{6}{|l|}{ Operational process discipline } \\
\hline Adherence and consistency & Yes & Yes & Yes & No & Somewhat \\
\hline \multicolumn{6}{|l|}{ Small internal team } \\
\hline Number of project team members & $<5$ & $<5$ & $<5$ & $15-20$ & $5-10$ \\
\hline Team interaction with other staff & Frequent & Frequent & Frequent & Limited & Limited \\
\hline \multicolumn{6}{|l|}{ Project management capabilities } \\
\hline Level of formal documentation & Medium & High & High & Medium & Low \\
\hline Project leader & Consultant & Consultant & Consultant & Staff & Staff \\
\hline \multicolumn{6}{|l|}{ External end user training } \\
\hline Source of end user training & External & External & External & Internal & Internal \\
\hline \multicolumn{6}{|l|}{ Management support } \\
\hline Financial support provided & Yes & Yes & Yes & Yes & No \\
\hline Staff motivated towards project & Somewhat & Yes & Yes & No & Somewhat \\
\hline Reduction in functional duties & Yes & Yes & Yes & Somewhat & No \\
\hline \multicolumn{6}{|l|}{ Qualified consultant } \\
\hline Soft skills & High & High & High & Medium & Low \\
\hline Business understanding & High & High & Medium & Low & Medium \\
\hline Software knowledge & High & Medium & Medium & Medium & Low \\
\hline
\end{tabular}


Table V. Critical success factors.

\begin{tabular}{ll}
\hline Factor & Rationale \\
\hline $\begin{array}{l}\text { Operational process } \\
\text { discipline }\end{array}$ & $\begin{array}{l}\text { Inconsistent operational processes conflict with the procedural rigidity of ERP. } \\
\text { Small internal team }\end{array}$ \\
$\begin{array}{l}\text { A team of less than five inherently interacts with end users, reaches consensus quickly, creates a sense of } \\
\text { project ownership, and reduces administration and coordination costs. } \\
\text { capabilities }\end{array}$ & $\begin{array}{l}\text { Internal project leaders are frequently distracted by regular tasks, limiting their time to prepare critical } \\
\text { project documentation. }\end{array}$ \\
$\begin{array}{l}\text { External end user } \\
\text { training } \\
\text { Management support }\end{array}$ & $\begin{array}{l}\text { Internal project teams often lack time and skill to preparing and delivering effective training sessions. } \\
\text { towards the project is just as important as providing sufficient resources. }\end{array}$ \\
Qualified consultant & Internal project teams may depend heavily on external consultants, their technical expertise and soft skills. \\
\hline
\end{tabular}


Table VI. Distinctive factors.

\begin{tabular}{ll}
\hline Factor & Rationale \\
\hline Part-time dedication & $\begin{array}{l}\text { Internal project team members were generally expected to carry on regular responsibilities during the } \\
\text { implementation. Project success was achieved despite this practice. }\end{array}$ \\
$\begin{array}{l}\text { Lack of formal } \\
\text { communication }\end{array}$ & $\begin{array}{l}\text { appeared to be directly associated with this decision. } \\
\text { Software modification }\end{array}$ \\
$\begin{array}{l}\text { Four of five companies chose to significantly modify their software, yet two of them had successful } \\
\text { projects. } \\
\text { Informal strategy }\end{array}$ & \begin{tabular}{l} 
Two of the three successful cases had no formal strategic planning or communication. \\
\hline
\end{tabular}
\end{tabular}

